\title{
Potential Autonomic Risk Factors for Chronic TMD: Descriptive Data and Empirically Identified Domains from the OPPERA Case- Control Study
}

\author{
William Maixner $1,2,3$, Joel D. Greenspan ${ }^{4}$, Ronald Dubner ${ }^{4}$, Eric Bair ${ }^{1,5}$, Flora Mulkey ${ }^{1,5}$, \\ Vanessa Miller ${ }^{1}$, Charles Knott ${ }^{6}$, Gary D. Slade ${ }^{1,7,8}$, Richard Ohrbach ${ }^{9}$, Luda \\ Diatchenko ${ }^{1,2,10}$, and Roger B. Fillingim ${ }^{11}$ \\ ${ }^{1}$ Center for Neurosensory Disorders, University of North Carolina at Chapel Hill Chapel Hill, NC \\ ${ }^{2}$ Department of Endodontics, University of North Carolina at Chapel Hill Chapel Hill, NC \\ ${ }^{3}$ Department of Pharmacology, University of North Carolina at Chapel Hill Chapel Hill, NC \\ ${ }^{4}$ Department of Neural and Pain Sciences, and Brotman Facial Pain Center, University of \\ Maryland Dental School, Baltimore, MD \\ ${ }^{5}$ Department of Biostatistics University of North Carolina at Chapel Hill, NC \\ ${ }^{6}$ Battelle Memorial Institute, Durham, NC \\ ${ }^{7}$ Department of Dental Ecology, University of North Carolina at Chapel Hill, Chapel Hill, NC \\ ${ }^{8}$ Department of Epidemiology, University of North Carolina at Chapel Hill Chapel Hill, NC \\ ${ }^{9}$ Department of Oral Diagnostic Services, University at Buffalo, Buffalo, NY \\ ${ }^{10}$ Carolina Center for Genome Sciences at Chapel Hill, Chapel Hill, NC \\ ${ }^{11}$ Department of Community Dentistry \& Behavioral Science, University of Florida, Gainesville, FL
}

\section{Abstract}

Several case-control studies have been conducted that examine the association between autonomic variables and persistent pain conditions; however, there is a surprising dearth of published studies in this area that have focused on temporomandibular disorders (TMD). The current study presents autonomic findings from the baseline case-control study of the OPPERA (Orofacial Pain: Prospective Evaluation and Risk Assessment) cooperative agreement. Measures of arterial blood pressure, heart rate, heart rate variability, and indirect measures of baroreflex sensitivity were assessed at rest and in response to a physical (orthostatic) and psychological (Stroop) stressors in 1633 TMD-free controls and 185 TMD cases. In bivariate and demographically adjusted analyses,

(C) 2011 The American Pain Society. Published by Elsevier Inc. All rights reserved.

Correspondence to: OPPERA Study, Center for Neurosensory Disorders, Rm 2111 Old Dental Building, University of North Carolina, Chapel Hill, N.C. 27599-7455, 919-966-0684 (Telephone), 919-966-3683 (FAX).

Disclosures: This work was supported by NIH grant U01DE017018 and P01NS045685. This material was also supported with by the North Florida/South Georgia Veterans Health System, Gainesville, FL. The OPPERA program also acknowledges resources specifically provided for this project by the respective host universities: University at Buffalo, University of Florida, University of Maryland-Baltimore, and University of North Carolina-Chapel Hill. Roger Fillingim and Gary Slade are consultants and equity stock holders, and William Maixner and Dr. Luda Diatchenko are officers and equity stock holders in Algynomics, Inc., a company providing research services in personalized pain medication and diagnostics.

Publisher's Disclaimer: This is a PDF file of an unedited manuscript that has been accepted for publication. As a service to our customers we are providing this early version of the manuscript. The manuscript will undergo copyediting, typesetting, and review of the resulting proof before it is published in its final citable form. Please note that during the production process errors may be discovered which could affect the content, and all legal disclaimers that apply to the journal pertain. 
greater odds of TMD case status were associated with elevated heart rates, reduced heart rate variability, and reduced surrogate measures of baroreflex sensitivity across all experimental procedures. Principal component analysis was undertaken to identify latent constructs revealing five components. These findings provide evidence of associations between autonomic factors and TMD. Future prospective analyses in the OPPERA cohort will determine if the presence of these autonomic factors predicts increased risk for developing new onset TMD.

\section{Keywords}

Temporomandibular Disorders; Heart Rate Variability; Blood Pressure; Heart Rate; Baroreflex Sensitivity; Stroop; Orthostatic

There is considerable evidence that enhanced pain sensitivity and psychological distress are risk factors ${ }^{1}$ for the onset and maintenance of temporomandibular joint disorders (TMD; for reviews see Maixner et al. in this volume, Diatchenko et al ${ }^{19}$ and Maixner ${ }^{59}$ ). In addition to these relatively well studied risk domains, emerging evidence indicates that dysregulation of the autonomic nervous system contributes to the onset and persistence or chronicity of TMD and related conditions. ${ }^{8}, 10,16,52,57,59,83$ To date only a handful of studies have systematically examined and compared autonomic function in TMD cases and controls under resting conditions and in response to physical and psychological stressors. $8,10,16,52,81,83$ However, there is a rather substantial literature on the autonomic profiles associated with fibromyalgia syndrome (FMS), a chronic musculoskeletal condition where over $50 \%$ of affected people also experience chronic TMD. ${ }^{22,} 53,54,60-62,68$ Some individuals with FMS display autonomic dysregulation that involves increased sympathetic nervous system (SNS) drive at rest coupled with deficient SNS-mediated responses to specific challenges such as postural change or exercise. ${ }^{28,60,62}$ Decreased heart rate variability (HRV) under awake resting conditions and during sleep is seen in FMS and is consistent with lesser parasympathetic and greater $\beta$-adrenergic tone. ${ }^{13,} 62,68$ Arterial baroreflexes, a brain stem system that is involved in regulating cardiovascular dynamics and pain perception, is also blunted in individuals with FMS.7, 37, 60, 79

Consistent with blunted baroreflex sensitivity, people with FMS show reduced heart rate (HR) and blood pressure (BP) responses during orthostatic challenges. ${ }^{7,}{ }^{26}$ Further evidence for a central nervous system (CNS) dysregulation in autonomic function in FMS patients is the finding of reduced plasma epinephrine (EPI) and norepinephrine (NE) responses, as well as decreased NE metabolites in cerebrospinal fluid, to stressors such as exercise or hypoglycemia. 28, 31, 48, 92 Compared to controls, individuals with TMD express lower ambulatory BP than controls ${ }^{16}$ and reduced plasma NE levels at rest and during a publicspeaking stressor procedure. ${ }^{15,52}$ Thus, an emerging literature implicates a CNS-mediated dysregulation of autonomic function at rest and in response to both physical and psychological stressors. This dysregulation contributes to the clinical signs and symptoms seen in patients with FMS, suggesting that it may also contribute to the signs and symptoms of TMD.

One aim of baseline case-control study of the OPPERA project (Orofacial Pain: Prospective Evaluation and Risk Assessment) was to assess autonomic profiles of people diagnosed with TMD arthralgia, myalgia or both ("TMD cases") and people who were found not to have TMD when examined ("controls"). Autonomic profiles were measured under resting

\footnotetext{
${ }^{1}$ Here, we define a risk factor as "An attribute or exposure that is associated with an increased probability of a specified outcome, such as the occurrence of a disease. Not necessarily a causal factor." 46
} 
conditions and in response to a physical stressor (i.e., orthostatic challenge) and a psychological/cognitive stressor (i.e., Stroop color-word and pain-word tests).

\section{Methods}

\section{Study setting and participants}

As described elsewhere (see Slade et al. in this volume for detailed description) the OPPERA baseline case-control study used advertisements, emails, flyers, and word of mouth to recruit people who had chronic TMD ("cases") and people who did not ("controls"). They were recruited between May 2006 and November 2008 from communities in and around academic health centers at four US study sites: Baltimore, MD; Buffalo, NY; Chapel Hill, NC; and Gainesville, FL. At each study site, the target was to recruit 800 controls and variable numbers of cases based on local operational requirements, for a total of 3,200 controls and 200 cases. The actual number enrolled was 3,263 controls and cases.

The classification of TMD was based on the Research Diagnostic Criteria for Temporomandibular Disorder. ${ }^{18}$ In summary, cases met all three of the following criteria: during the telephone interview, (i) pain reported with sufficient frequency in the cheeks, jaw muscles, temples, or jaw joints during the preceding six months (at least 15 days in the preceding month and at least five days per month in each of the five months preceding that); during the examination, (ii) pain reported in the examiner-defined orofacial region for at least 5 days out of the prior 30 days; and (iii) pain reported in at least three masticatory muscles or at least one temporomandibular joint in response to palpation or to maneuvering of the jaw. Examiners defined the orofacial region by touching the following anatomical areas bilaterally: temporalis, preauricular, masseter, posterior mandibular, and submandibular. Controls met all five of the following criteria: during the telephone interview, (i) pain reported infrequently in the cheeks, jaw muscles, temples, or jaw joints (no orofacial pain in the preceding month and no more than four days per month in any of the five months preceding that); (ii) no more than four headaches per month within the preceding three months; (iii) never diagnosed with TMD; (iv) no use of a night guard occlusal splint; and during the examination, (v) pain reported in the examiner-defined orofacial region for no more than 4 days in the prior 30 days. However, controls could be positive or negative with respect to pain in response to palpation or jaw maneuver. Additional study-wide criteria for all study participants were aged 18-44 years, fluent in English, not receiving orthodontic treatment, and not pregnant or nursing, and had negative responses to each of 10 questions about significant medical conditions and no history of facial injury or surgery.

This analysis uses data from all 185 recruited TMD cases and one half of the 3,263 recruited controls (1,633 people). The controls for this analysis were selected at random so that data from people in the reserved sample could be used for validation studies that will be reported elsewhere. The accompanying paper (see Slade et al., in this volume) gives a more detailed account of study recruitment, case-classification methods, and inclusion and exclusion criteria.

\section{Ethical conduct of research with humans}

The OPPERA study was reviewed and approved by institutional review boards at each of the four study sites and at the data coordinating center, Battelle Memorial Institute. All study participants verbally agreed to a screening interview done by telephone and they provided written consent for all other study procedures. 


\section{Autonomic Profiling Protocols}

During the 3-hour baseline clinic visit, autonomic profiles were measured for all participants in five periods: (1) a 20-minute rest period that followed the clinical examination; (2) a 5minute orthostatic challenge period that followed Period 1; (3) a 10-minute rest period that followed assessments of thermal and mechanical pain sensitivity, (4) a period of approximately 5 minutes following Period 3, during which the traditional Stroop ColorWord test was administered, and (5) a period of approximately 5 minutes following Period 4 , during which the Stroop Pain-Affect test was administered ${ }^{2}$.

At the beginning of the first period, a blood pressure cuff, which completed a single reading in approximately 35 seconds, was placed on the upper left arm and was inflated with a Datascope Accutorr Plus blood pressure monitor (Datascope Inc, Mahwah, NJ). HRV was assessed with a three lead BioCom model 3000 Heart Rhythm Scanner (Biocom Technologies. Poulsbo, WA) with the electrical leads positioned at the following locations: left 2nd rib (ground), right 2nd rib, and lower left torso. ECG signals were checked for impedance (below $300 \mathrm{KOhm}$ ), digitized (1024 samples per second), filtered for artifacts ${ }^{3}$, and displayed in real-time on a laboratory computer. Participants could not see the instruments' displays. Participants were placed in a zero-gravity exam chair ((http://sitincomfort.com/zerrec.html) and fully reclined (supine position) in a room with soft lighting. Once the participant was reclined, they were read the following instructions:

"During this rest period, please stay quiet and remember not to cross your legs even at the ankles. I will let you know when the rest period is complete but I cannot talk to you during the rest period."

Blood pressure ((BP)—systolic (SBP) and diastolic (DBP)—mean (MAP) pressures), and HR measures were assessed every 2.5 minutes for 20 minutes.

At the beginning of the second period, participants were provided with the following instructions:

"Now I am going to ask you to stand up as quickly as you can but first please listen to my instructions. I am going to count to 3 and I would like you to use your right arm to help yourself out of the chair and stand up with both feet flat on the floor. It is very important that you stand up as fast as you can. If you should happen to feel dizzy or lightheaded let me know and remember the chair will be behind you. Do you have any questions?"

$\mathrm{BP}$ and HR were recorded within 30 seconds of standing and $\mathrm{BP}$ and HR measures were obtained at 1 minute intervals for the next 5 minutes. HRV was assessed over the duration of the 5 minute orthostatic period.

For Periods 3, 4, and 5, participants were positioned in a chair facing a computer with four buttons colored yellow, green, blue, and red. Following the 10 minute rest period (Period 3), and a training period with the computer, participants were exposed to a 5-minute

\footnotetext{
${ }^{2}$ The results associated with the QST aspects (thermal, pressure, mechanical) of the protocol are reported elsewhere in this compendium (see: Greenspan, et al. Pain Sensitivity Risk Factors for Chronic TMD: Descriptive Data and Empirically Identified Domains from the OPPERA Case Control Study. Because of time constraints associated with the protocol, autonomic testing was not performed during the administration of painful stimuli.

${ }^{3}$ Noise free, real-time signals were first documented by the technician to assure that traces with very sharp R-peaks were being recorded. Software intrinsic to the device detected the near proximity of the R-peak and values that deviated by more than $30 \%$ of the normal previous normal heart rate reading were tagged and rejected. The software is also capable of detecting various types of abnormal heartbeats resulting from several causes. The following statistical steps were performed by the device implemented to assess and reject artifacts: 1) Linear trends were removed from the HR data record, 2) mean HR and standard deviation of HR was calculate and 3) each HR reading was tested to determine if it belonged to the normal HR data pool based on the Student t-test. Abnormal or out of range HRs were visually tagged and removed from the analysis.
} 
computerized version of the Stroop Color-Word task ${ }^{86}$ Weisseman-Fogel and coworkers ${ }^{91}$ have shown that TMD patients show abnormal cortical activity evoked by the type of cognitive and emotional STROOP stimuli used in this study. (Period 4). Participants were told "During this procedure, the words YELLOW, GREEN, BLUE, or RED appear on the screen in the colors yellow, green, blue or red in a randomly assigned manner." The participant was instructed to press the button corresponding to the color of the word displayed on the screen (e.g., if the word RED appeared in yellow the correct response was to depress the yellow key). During Period 5, the Stroop Pain-Affect task was administered. ${ }^{71}$. Words with different psychological valances [i.e., neutral words (garden, armchair) vs. words associated with pain and affect (throbbing, miserable)] appeared in the colors yellow, green, blue, or red and the participant's task was to press the button corresponding to the color of the word displayed on the screen (e.g., if the word BLOOD appeared in green the correct response was to depress the green key). The sequence of word presentation and tabulation of results was done using DirectRT hardware and software (Empirisoft, NY, NY). Throughout Periods 3, 4, and 5, BP and HR values were assessed at 1-minute intervals. HRV was recorded continuously during each of the 5-minute Stroop procedures. The autonomic measures were averaged over the 5 minute Color and the 5minute Pain-Affect Stroop epoch.

\section{Derived Autonomic Measures}

Measures of Arterial Blood Pressure and Heart Rate-BP values were recorded in $\mathrm{mmHg}$ and $\mathrm{MAP}$ was derived using the following formula: $\mathrm{MAP}=(\mathrm{SBP}+2 * \mathrm{DBP}) / 3$. Heart rate was measured coincidence with measures of arterial $\mathrm{BP}$ in beats-per-minute (bpm).

Measures and Analyses of HRV-For reviews on the measurement and interpretation of HRV variables see the recommendations provided by the Task Force of the European Society of Cardiology and the North American Society of Pacing and Electrophysiology ${ }^{1}$ and by Berntson et al. ${ }^{6}$ Time Domain Measures: Heart Rate was measured as inter-beatintervals and a reciprocal value was calculated to derive HR values as beats-per-min (bpm). SDNN (standard deviation of normal-to-normal $[\mathrm{N}-\mathrm{N}]$ intervals) is the standard deviation of cardiac cycle inter-beat intervals, measured in milliseconds, and it reflects all cyclic components of the variability in the recorded series of inter-beat-intervals. RMSSD (root mean square of the differences between successive N-N intervals) is the square root of the mean squared differences of successive inter-beat-intervals, measured in milliseconds, and is an estimate of high-frequency variations in heart rate in short-term recordings that reflects an estimate of parasympathetic regulation of the heart. Frequency Domain Measures: Total Power (TP) is a short-term estimate of the total power of power spectral density in the range of frequencies between 0 and $0.4 \mathrm{~Hz}$. This measure reflects overall (cardiosympathetic and cardioparasympathetic) autonomic activity. Very Low frequency (VLF) is a band in the power spectrum ranging between 0.0033 and $0.04 \mathrm{~Hz}$. This measure is not well defined in terms of physiological mechanisms; however, activity in this frequency band has been associated with regulation of the renin-angiotensin system and used as an indicator of activity of slow temporal processes regulated by the sympathetic nervous system. Low Frequency (LF) is a band of the power spectrum that ranges between 0.04 and $0.15 \mathrm{~Hz}$ and reflects both sympathetic and parasympathetic activity. It is a strong indicator of sympathetic activity in long-term recordings. Parasympathetic influence is represented in the LF band when respiration rate is lower than seven breaths per minute or during a valsalva procedure. Thus, when a participant is in the state of relaxation with a slow and even breathing, LF values are indicative of increased parasympathetic activity rather than increased sympathetic regulation. Activity in the LF band has also been related to baroreflex sensitivity with higher values associated with greater baroreflex sensitivity. ${ }^{12,} 72,82,88,89$ Greater baroreceptor sensitivity produces greater reflex changes in HR for a given change in 
MAP and is associated with enhanced baroreflex cardioparasympathic responses to a given change in mean arterial pressure. High Frequency (HF) is a band of the power spectrum that ranges between 0.15 and $0.4 \mathrm{~Hz}$ and reflects parasympathetic activity. $\mathrm{HF}$ is also known as a respiratory band because it corresponds to the inter-beat-interval variations influenced by respiratory sinus rhythm. Slower and even breathing causes an increase in cardioparasympathetic activity and the amplitude of the HF peak in the power spectrum. Frequency domain measures are calculated in milliseconds squared $\left(\mathrm{ms}^{2}\right)$.

\section{Data Analysis}

HRV Data-For time domain parameters : Mean HR were excluded if not between 40-200 bpm, Mean RR had to be within 400-2000 ms, SDNN ratings were between 10-500 ms, and finally RMSSD measures were within the range 10-1000 ms. Frequency domain parameters had the following limits: Total Power (TP) 10-10,000 ms 2 , Very Low Frequency (VLF) 10$6000 \mathrm{~ms}^{2}$, Low Frequency (LF) 10-6000 $\mathrm{ms}^{2}$, and High Frequency (HF) 10-6000 ms². Only high-quality ECG signals were collected and subjected to artifact detection and cleaning using Biocom Heart Rhythm Scanner software (version 2.0). After filtering for out of range time and frequency domain values, an additional data quality check was performed to assure that the TP value was greater than the sum of the HF, LF, and VLF values. The frequency domain measures (TP, HF, LF, VLF) were strongly right-skewed so a logarithmic transformation was performed on the absolute units of these spectral bands to diminish this effect.

BP and HR Data-SBP measurements were excluded if outside the range of 60-220 mmHG. DBP measures had to be within 40-110 mmHG. HR measures during the reclined period had to be between 30-175 bpm. During all other periods, orthostatic, Stroop-baseline, color-word, pain-affect had to be between 40 and $200 \mathrm{bpm}$.

For the Rest Period (1), Mean BP measures (SBP, DBP, MAP, and HR) were averaged over the last three recordings assessed at minutes $15,17.5$, and 20 during the rest period. For the Orthostatic Period (2), the changes in BP: $\triangle \mathrm{SBP}, \triangle \mathrm{DBP}, \triangle \mathrm{MAP}$, and $\triangle \mathrm{HR}$ from the values obtained during the Rest Period were determined by subtracting the first value measured in the orthostatic period from the mean values obtained at minutes 15, 17.5, and 20 during the rest period. For the Stroop Periods (4\&5): mean BP measures (SBP, DBP, MAP, and HR) were averaged over the five minute data collection period at minutes 1:00, 2:00, 3:00, 4:00 and 5:00. Changes in BP: $\triangle \mathrm{SBP}, \triangle \mathrm{DBP}, \triangle \mathrm{MAP}$, and $\Delta \mathrm{HR}$ from the pre-Stroop values (Period 3) were determined by subtracting the average value measured in the pre-Stroop period at minutes 5:00, 7:30, and 10:00 from the mean of the values obtained during the Stroop tasks, with values at minutes 1:00, 2:00, 3:00, 4:00 and 5:00 to compute the mean value.

The ratio of HR $\div$ MAP was computed as a measure of the relative balance of cardiosympathetic versus cardioparasympathetic (vagal) tone at a given baroreflex set point (MAP). Higher values reflect greater cardiosympathetic versus cardioparasympathetic tone while lower values signify greater cardioparasympathetic versus cardiosympathetic tone at a given baroreceptor set point. ${ }^{2,35,90}$

Imputation for missing values used the EM method in SAS proc MI which finds maximum likelihood estimates for incomplete data under the assumption that the data are multivariate normal. ${ }^{80}$ Descriptive statistics for each summary score were generated using non-imputed data. Statistical significance of differences in mean scores was evaluated using the t-test derived from a least squares linear model in which study site was a covariate. Study site was used as a covariate because operational requirements during recruitment created different proportions of cases among sites (see Slade for further details). The relationship between 
each summary score and occurrence of TMD was expressed as the standardized odds ratio (SOR), calculated from an unconditional, binary logistic regression model with study site as a covariate. To achieve this, the summary score was transformed to a unit-normal deviate. The transformation meant that odds ratios could be interpreted as the relative change in odds of TMD for each standard deviation of change in the summary score. A second logistic regression model generated a fully-adjusted estimate of the relationship, using additional covariates of age (in years), gender, and race/ethnicity (dichotomized as white or nonwhite). A third logistic regression model using this imputed dataset calculated SORs for each summary score, with adjustment for the same covariates as in the prior model. Odds ratios with values less than 1.0 were reverse coded for ease of presentation and interpretation.

All P-values were computed without adjustment for multiple tests, and we therefore refrain from designating $\mathrm{P}=0.05$ as a threshold for statistical significance. In this paper's casecontrol analysis, up to 15 autonomic variables were investigated for any experimental condition, Resting epoch assessed 11 variables (Note: blood pressure cuff assessed Mean HR is equivalent to ECG assessed Mean HR (HRV) and were treated as a single entity for this calculation), Orthostatic epoch 11 variables, Stroop Color Word epoch 15 variables and Pain-Affect 15 variables. Therefore, the most conservative Bonferroni correction for the probability of type I error for a given experimental period would yield a critical P-value of $0.05 \div 15=0.003$. Using the same rationale, rejection of the null hypothesis concerning odds ratios would occur only if the $99.6 \%$ confidence interval excluded the null value of one. In general, though, we avoid drawing conclusions about statistical significance of associations, even with correction for multiple tests, because these papers report only univariate- or demographically-adjusted results. Furthermore, the Bonferroni adjustment is probably overly-conservative in this setting, where several measures are moderately correlated. Instead, we will reserve judgments about statistical significance to subsequent papers that will use multivariable modeling to consider multiple characteristics simultaneously, as proposed in the OPPERA heuristic model (Maixner et al. this volume).

Principal component analysis (PCA) was applied to this data set to identify putative latent variables. The approach began with four steps, widely used in exploratory principal component analysis $^{69}: 1$ ) variable selection; (2) evaluation of the correlation matrix; (3) extraction of initial components; and (4) rotation and interpretation of component loadings. This model is being used for purely exploratory purposes with regards to the structure of the latent variables and not for computation of summary scores for the various components.

Our primary interest focused on PCA loadings in controls for three reasons: (a) there are many more controls than cases, thereby improving statistical power to identify factors and estimate loadings; (b) our underlying conceptual model of TMD (see Maixner et al. in this volume) proposes that relationships between putative risk factors might alter following onset of chronic pain, and we wanted to evaluate that possibility; and (c) the long-term goal of OPPERA is to identify risk factors for TMD among controls, so it is desirable to identify a reduced set of variables for that group. Thus, we fit separate PCA models for the TMD cases and controls.

We elected to keep the 42 variables listed in Table 6 in the model even though some of the variables were highly correlated with one another. We wanted to determine which measures could be combined into latent variables, and this required that all the variables be retained in the model. Although this has the potential to increase the variance of our estimates of the PCA loadings, this was not a major concern given our large sample size. As shown below, we estimated the variance of our PCA loadings using bootstrapping, and these variances were uniformly low despite the correlations among the input variables. The only variables 
we did not include in the model were variables derived from two or more of the underived variables (e.g., HR/MAP Index), since the inclusion of such variables would create both computational and interpretative difficulties.

After imputing missing values as described above, 348 subjects still had at least one missing value among the variables included in the model. Because missingness may be non-random, we were concerned with bias if we dropped these 348 subjects from the model. To avoid this potential bias, we performed a second round of imputation. Specifically, we imputed any missing BP measures based on the observed BP measurements in the same epoch and we imputed missing HR measurements based on the observed HR measures in the same epoch. We then imputed any remaining missing BP measurements based on observed BP measurements in other epochs and missing heart measures based on observed HR measures in other epochs. We used the EM algorithm to perform this imputation under the assumption that the data are multivariate normal, as described previously. After performing this second round of imputation, there were only nine remaining subjects with missing data. It should be noted that we report the SOR's for both the imputed and unimputed data sets (see Tables 14), and in all cases the results are extremely similar (if not identical). And while we do not report these results, we also fit our PCA model using only unimputed data, and we obtained a model very similar to the model reported in the manuscript.

We examined a scree plot to estimate the number of components to include in the model (Figure 1). The variance explained by each principal component decreased most conspicuously after the fifth component, suggesting that at least five components are needed. We used parallel analysis to verify this estimate. Parallel analysis estimates the number of components to include in a PCA model by generating random data sets with the same numbers of observations and predictor variables as the original data. The eigenvalues are computed for each random data set and averaged over all the data sets. When the average eigenvalue from these randomly generated data sets is larger than the corresponding eigenvalue of the original data, then the principal component associated with that eigenvalue is likely to be random noise. The parallel analysis also showed strong evidence that components one through five were above the chance line (Figure 1). Components six, seven, and eight were near the chance line, so it was unclear if they should be included in the model.

We therefore fit PCA models using five, six, seven, and eight components. The bootstrap confidence intervals for components six, seven, and eight were very wide for many of the loadings, suggesting that the estimated loadings were unstable. (Data not shown) However, the confidence intervals for the loadings of the first five components were very narrow, indicating a stable (and accurate) model. Additionally, the Cronbach's alpha values for these five components were very high-ranging from 0.92-0.96-further supporting a good reliability of this model. Thus, we report a model based on five components.

PCA models were fit using the R statistical computing platform. All variables were normalized to have mean 0 and standard deviation 1 prior to fitting the models. After calculating the PCA eigenvectors, a promax rotation was applied to increase the interpretability of the resulting PCA loadings. The promax rotation produced loadings that were easier to interpret than the loadings resulting from orthogonal rotations, and other nonorthogonal rotations produced similar results. The rotated loadings are presented unless otherwise noted. The variance in the PCA loadings of each model was estimated by drawing 1000 bootstrap samples for each data set and fitting a PCA model for each replicate. The 95\% confidence bounds for the PCA loadings were estimated to be the $2.5 \%$ and $97.5 \%$ quantiles of the corresponding loading over the 1000 bootstrap replicates. ${ }^{21}$ 
We performed a series of permutation tests to test the null hypothesis that the loadings were the same for both the control and TMD models, and we found that these differences were not statistically significant, particularly considering that we are performing multiple hypothesis tests (Supplementary e-Table 20). It is unclear if the loadings are truly identical for both models or if we simply do not have power to detect the difference given the relatively small number of TMD cases. The confidence intervals for the PCA loadings in the model based on TMD cases are very wide for components 2-5 (Supplementary e-Table 19). This is not surprising, given that the case sample size was relatively small, but it indicates that the estimates of these loadings have high variance and may not be reliable.

\section{Results \\ Case-Control Differences 4}

Autonomic Profiles During the 20 min Rest Period- (Table 1)_As shown in Table 1 , average DBP and HR (cuff and inter-beat-interval) assessed during the resting period were greater in cases compared to controls, yielding SORs of 1.2 that did not change appreciably after adjustment or imputation. Resting measures of SBP and MAP did not differ between the two groups. The Resting HR $\div$ MAP Index was greater in cases than in controls, with corresponding SORs of 1.2 (site-adjusted) and 1.1 (fully-adjusted and imputed). Odds ratios and their 95\% confidence intervals were similar with and without adjustment for missing data (imputed) and demographic characteristics. These finding suggests that under resting conditions, TMD case and controls have equivalent resting baroreflex set points (i.e., MAP's $83.5+.61 \mathrm{vs} 82.8+.21 \mathrm{mmHG}$ ) but due to the elevated resting HR observed in TMD cases they may have a bias towards greater cardiosympathetic versus cardioparasympathetic tone compared to controls. HRV measures also differed between cases and controls. TMD cases showed lower values than controls in both time (SDNN, RMSSD) and frequency (TP, VLF, LF, HF) domains. Corresponding SORs ranged from 1.2-1.3 and were similar after adjustment for demographic characteristics. These findings suggest that under resting conditions, TMD patients show reduced HRV compared to controls. The reduced power seen in the LF band in cases compared to controls is also consistent with reduced baroreflex sensitivity, which contributes to the elevations in HR and bias towards greater cardiosympathetic versus cardioparasympathetic tone observed in cases. $^{2,24,35,90}$ The small increase in DBP observed in cases is also consistent with increased sympathetic drive due to either an increase in peripheral vascular resistance and/or increased HR both of which can increase arterial tone and diminish arterial relaxation time.

\section{Autonomic Profiles during Orthostatic Challenge - A Physiological Stressor (Table 2)-Mean changes $(\Delta \mathrm{s})$ in SBP, MAP, and HR from rest to the first 30 to 60 seconds of the orthostatic challenge were similar for cases and controls (Table 2). \\ Corresponding change in DBP was marginally greater, on average, in controls compared to cases, although the SOR was not significant after adjustment for demographic characteristics. HRV measures also differed between cases and controls with lower values observed among cases in both the time (SDNN, RMSSD) and frequency (TP, VLF, LF, HF) domains. Corresponding SORs ranged from 1.1-2.2. Odds ratios and their 95\% confidence intervals were similar with and without adjustment for demographic characteristics. Similar to the results observed under resting conditions, the orthostatic challenge was associated with reduced HRV compared to controls and the reduced power seen in the LF band in cases compared to controls is also consistent with reduced baroreflex sensitivity, which}

\footnotetext{
${ }^{4} \mathrm{~A}$ complete description of demographic distributions, including age and gender is contained in the article by Slade, et al in this Compendium which also reports that $85 \%$ of the cases were myalgia + arthralgia, and the remaining $15 \%$ was roughly equally allocated to myalgia alone and to arthralgia alone. Given the relatively small cell sizes associated with the TM-joint and myalgia only groups we elected to not differentiate the population into multiple subgroups.
} 
contributes to a bias towards greater cardiosympathetic versus cardioparasympathetic tone in cases during the orthostatic challenge.

\section{Autonomic Profiles During Stroop Procedures - Psychological Stressors - (Tables 3 and 4)}

Stroop Color-Word Procedure: As shown in Table 3, the mean change $(\Delta)$ in SBP, MAP, and HR evoked over the 5-minute Color-Word Stoop, as compared to values recorded during the pre-Stroop resting period, did not differ between cases and controls. The $\triangle \mathrm{DBP}$ response was marginally greater in controls compared to cases and the SOR was 1.2. As shown in Table 3, cases showed greater HR responses (cuff and inter-beat-interval) averaged over the 5-minute observational period compared to controls. SBP, DBP and MAP responses averaged over the same time period did not differ between the two groups. Standardized odds ratios (SORs) for case status were 1.4 for HR. The Color-Word Stroop HR $\div$ MAP Index averaged over the same time period was also greater in cases than in controls, with an SOR of 1.3 that did not change appreciably after adjustment and imputation. Cases showed lower values for heart rate variability in both time (RMSSD) and frequency (TP, VLF, LF, HF) domains. Corresponding SORs ranged from 1.2-1.4. Odds ratios and their $95 \%$ confidence intervals were similar with and without adjustment for demographic characteristics.

Pain-Affect Stroop Procedure: Similar to the Color-Word Stroop test, the mean change $(\Delta)$ in SBP, MAP, and HR evoked over the 5-minute Pain-Affect Stoop, as compared to values recorded during the pre-Stroop resting period, did not differ between cases and controls (see Table 4). In contrast to the Stroop Color Word-evoked $\triangle D B P$ response, the Pain-Affect Stroop test evoked a slight reduction in $\triangle \mathrm{DBP}$, which was greater in controls compared to cases $(-1.28+0.14$ vs $-0.11+0.40 ; \mathrm{p}<0.008)$. The corresponding SOR was 1.2 , an effect that persisted after adjustment for demographics and after imputation. Average DBP and HR (cuff and inter-beat-interval) responses were greater in cases compared to controls over the 5-minute assessment period. In contrast, average SBP and MAP values collected over this same time period did not differ between the two groups. SORs were 1.2 for DBP and 1.4 for HR. The HR $\div$ MAP Index averaged over the same time period also differed between the two groups with a higher index observed in cases, and corresponding SOR of 1.3. Odds ratios and their $95 \%$ confidence intervals were similar after adjustment for demographics and with imputation for missing data. Cases had lower values than controls in both time (SDNN and RMSSD) and frequency (TP, VLF, LF, HF) domains of heart rate variability. Corresponding SORs ranged from 1.2-1.4 and were similar with and without adjustment for demographic characteristics.

These findings suggest that the Color-Word and Pain-Affect Stroop procedures are associated with reduced HRV in cases compared to controls. The reduced power seen in the LF band in cases compared to controls is also consistent with reduced baroreflex sensitivity during the Stroop procedures, which contributes to the elevations in HR and a bias towards greater cardiosympathetic versus cardioparasympathetic tone observed in cases.

\section{Associations with Demographic Variables (Controls Only)- A Brief Summary} of Findings-A summary of the relationship between demographic variables and autonomic variables assessed in all four test periods can be found in Table 5. In brief, during all four procedures, all BP measures were associated with greater age, male gender, and nonwhite race-with the single exception of resting DBP. In nearly all procedures, greater HR was associated with female gender and non-white race, but not with age. The HR $\div$ MAP index was generally less with greater age and male gender. In most procedures, changes in $\mathrm{BP}$ and HR were either inconsistently related or greater for younger age and male gender. In 
nearly all procedures, all HRV measures were negatively associated with greater age and they were higher in males than in females. In all procedures, measures of VLF and LF were greater in whites than non-whites, and in the orthostatic procedure the TP was also greater in whites than in non-whites. In general, these demographic patterns tended to be stable across procedures. A detailed description of the relationships between demographic variables and autonomic variables can be found in Supplementary e-Tables 1-4 (Age), Supplementary eTables 5-8 (Gender), and Supplementary e-Tables 9-12 (Race/Ethnicity).

Distributions of Autonomic Measures-The mean, minimum, and maximum values and distribution $\left(5^{\text {th }}-95^{\text {th }}\right.$ percentiles) for each autonomic variable measured during the Rest Period (Supplementary e-Table 13), Orthostatic Challenge (Supplementary e-Table 14), Color-Word Stroop test (Supplementary e-Table 15), and the Pain-Affect Stroop test (Supplementary e-Table 16) are presented in the e-Supplement.

Principal Component Analysis-The loadings for the PCA model for controls are shown in Table 6, and the 95\% confidence intervals for the loadings are shown in Supplementary e-Tables 17-19. The confidence intervals are uniformly narrow, indicating that these results are stable.

The first component, accounting for $18 \%$ of the variance, labeled Blood Pressure Component, includes high loadings from SBP, DBP, and MAP across all protocols (Rest, Orthostatic, and Stroop). The second component, labeled Stroop HRV, based on high loadings from both time (with the exception of HR) and frequency HRV domains collected during both the Color and Pain-Affect Stroop tests accounted for an additional 16\% of the variance. The third component, Heart Rate, accounted for an additional $14 \%$ of the variance and included high loadings for measures of HR across all protocols (Rest, Orthostatic, and Stroop). The fourth component is labeled Resting HRV and accounted for an additional 12\% of the variance and is based on high loadings from both time (with the exception of HR) and frequency HRV domains collected during the 20 minute resting period. The fifth component is labeled Orthostatic HRV and accounted for an additional $10 \%$ of the variance and is based on high loadings from both time (with the exception of HR) and frequency HRV domains collected during the orthostatic assessment period.

The loadings and 95\% confidence intervals for the PCA for TMD cases are shown in Supplementary e-Table 19. The number of components and associated loadings were similar to that observed for controls. These confidence intervals are wider than observed for controls; with the exception of the loadings for the first component, essentially all of the loadings for the PCA in cases have very wide confidence intervals. This indicates that (with the exception of component one), this factor structure may not be reproducible. The higher variance in the loadings of the PCA for TMD cases is probably due to its much smaller sample size. Despite its high variance, the PCA model for cases was extremely similar to the model for controls. The differences in the loadings of the two models were generally very small. We performed a series of permutation tests to formally test the null hypothesis that these loadings were equal (Supplementary e-Table 20), and we found no evidence of case/ control differences in the loadings (particularly after adjusting for the fact that we performed multiple hypothesis tests).

\section{Discussion}

This is the first large scale case-control study that has systematically examined resting and stress-evoked autonomic profiles in chronic TMD cases and controls. While the case-control study design does not ascertain whether change in autonomic activity might be a cause or consequence of TMD, several of the observed associations provide grounds for further 
investigation of potential etiologic influences of autonomic activity. The primary findings that have emerged from these initial studies of potential risk factors are:

1. Relative to controls, TMD cases displayed a dysfunction in autonomic activity characterized by reduced HRV at rest and in response to both physical (orthostatic) and psychological (Color Word and Pain Affect Stroop tests) stressors. This is reflected by a decrease in all HRV measures in both the time and frequency domains during each of the test epochs. Measures of HRV were related to the odds of case status across all experimental epochs providing SORs ranging from 1.2-2.2. The largest SOR (2.2 for RMSSD) for case status was associated with the orthostatic epoch and is a reflection of decreased cardioparasympathetic responses to the orthostatic challenge.

2. Relative to controls, TMD cases display higher HRs when engaged in physical (orthostatic) and psychological (Stroop tests) tasks. These findings are consistent with the HRV results, which showed across all time and frequency domains reduced cardioparasympathetic tone compared to controls. Measures of HR were related to odds of case status across all experimental epochs providing SORs ranging from 1.1-1.4. The largest SOR (1.4) for case status was associated with both the Color-Word and Pain-Affect Stroop tasks. These findings are consistent with a central dysregulation which results in a relatively higher cardiosympathetic tone in cases during resting as well as during physically and psychologically stressful procedures.

3. Relative to controls, TMD cases displayed a reduction in an indirect index of baroreceptor sensitivity. This is reflected by a decrease in LF band values at rest and during the orthostatic and Stroop tasks. Measures of LF were related to the odds of case status across all experimental epochs providing SORs ranging from 1.2-1.4. The largest SOR (1.4) for case status was associated with the orthostatic epoch. The putative reduction in baroreceptor sensitivity is consistent with the reduction in HRV measures of cardioparasympathetic tone and the bias towards greater cardiosympathetic tone in TMD cases relative to controls.

4. The results of the PCA suggest that BP (Component 1) and HR (Component 3) measures tend to be strongly correlated across the various epochs, but HRV measurements (Components 2, 4, and 5) tend to be less correlated across different epochs. Thus, measuring a subject's BP or HR during an orthostatic challenge or Stroop test may provide minimal additional information if their resting BP/HR is known, but the HRV measurements taken during the physical and psychological challenges may contain more information beyond the information obtained by measuring the $\mathrm{HRV}$ at rest.

5. Age, Gender, and Race/Ethnicity autonomic profiles showed that in general higher $\mathrm{BP}$ measures were associated with greater age, male gender, and non-white race. Greater HR was associated with female gender and non-white race, but not with age. The HR $\div$ MAP index was smaller with greater age and male gender. In nearly all procedures, all HRV measures were negatively associated with greater age and they were higher in males than in females.

\section{Heart Rate Variability - TMD and Related Conditions}

Coupled with the findings we present here, there is emerging evidence that somatosensory disorders such as TMD and FMS are associated with a reduction in HRV (i.e. TP, HF, LF, VLF bands) and an overall dysfunction in autonomic activity. ${ }^{10,13,78,79,81,83}$ To date, only a few studies have examined HRV in TMD cases ${ }^{10,81,83}$. Two recent publications by Schmidt and coworkers ${ }^{81}$ and Solberg Nes and coworkers ${ }^{83}$ have examined the relationship 
between LF and HF variables and emotional reactivity and self-regulatory deficits in TMD participants with masticatory pain. In the former study, TMD patients showed reduced HF values at baseline and reduced levels during the recovery period following the recall of a personally relevant negative life experience. In cases, LF values tended to be elevated at baseline and were significantly elevated during the $10 \mathrm{~min}$ post-stress task recovery period. The authors suggest that this profile in TMD cases is consistent with a compromised inhibitory control of sympathetic activity resulting in prolonged increases in cardiosympathetic and decreased cardioparasympathetic activity during rest and following life-relevant psychological stressors. In a follow on study ${ }^{83}$, the relationship between HRV and measures of "self regulatory strength", which refers to one's ability to exercise control, guide and alter reactions and behaviors to environmental stimuli, was examined in a cohort of FMS and TMD participants. Higher baseline HF values were associated with higher self regulatory strength, which was indexed by the persistence in attempting to solve a difficult cognitive problem. The association of higher HF with persistence was observed in control participants and showed essentially no or minimal association in FMS and TMD cases.

Alterations of the LF band have also been observed in FMS cases under different conditions. The LF band has been shown to be either increased or decreased in FMS under resting conditions and in response to physical and psychological stressors. ${ }^{78,79}$ The functional interpretation of the relationship between the LF band and autonomic activity is controversial. Historically, the LF band has been suggested to represent sympathetic cardiac activation and the $\mathrm{LF} / \mathrm{HF}$ ratio has been proposed as a parameter of cardiosympathovagal balance. ${ }^{1,6,84}$ However, this historical view has been challenged because vagal blockade with atropine reduces the spectral power in all frequency bands, including the LF band and $\beta 1$-adrenergic blockade produces ambiguous effects on specific bands of HR. ${ }^{6,}{ }^{45}$ This has led to a revised model where all frequency bands contribute to parasympathetic tone. As such, the LF band and the LF/HF ratio are no longer viewed as valid indices of sympathetic cardiac tone. 6,34

Collectively these findings, when taken in the context of current day understanding of the functional significance of HRV, suggest that TMD is associated with reduced inhibitory parasympathetic and excitatory sympathetic tone, but the overall autonomic balance and end organ responses are biased towards the sympathetic nervous system, which is consistent with the elevations in HR observed in TMD, FMS, and chronic myofascial pain at rest and during physical and psychological stressors. ${ }^{68,78,79}$

\section{Baroreceptor Sensitivity - TMD and Related Conditions}

The relative reduction in LF values, increase in HR values, and increase in HR $\div$ MAP Index observed in TMD cases versus controls at rest and during orthostatic and Stroop procedures suggests that TMD may be associated with impaired baroreceptor sensitivity, which contributes to the relative sympathetic nervous system bias seen in TMD cases. The outcomes of multiple studies have linked baroreceptor function to pain sensitivity and psychological function. ${ }^{9,} 56,57,59,76-79$ There is also evidence that chronic pain conditions, including TMD, are associated with a baroreceptor mediated dysregulation of pain perception. For example, TMD cases fail to show the typical relationship between resting mean arterial BP, which is the primary physiological stimulus of the carotid sinus baroceptor system, and pain perception. ${ }^{58}$ FMS is also associated with autonomic abnormalities that are consistent with impairments in baroreceptor function. ${ }^{7,13,67,70,74}$ Recently Reyes Del Pase et $\mathrm{al}^{78,79}$ showed that baroreflex sensitivity is reduced in individuals with FMS at rest and during physical and psychological stressors. They also demonstrated that the reduction in baroreflex sensitivity is associated with reduced cardioparasympathetic tone, increased resting heart rate and heart rate responses to physical and psychological stressors, as well as enhanced clinical pain report and sensitivity to experimental pain stimulation. The observed 
reductions in HRV, baroreflex activity and elevations in HR are not only seen in TMD and FMS patients, but appear to be a common feature associated with multiple complex persistent pain conditions that are associated with somatic awareness. ${ }^{42}$

The increase in HR observed in TMD cases across all study conditions is also consistent with diminished baroreflex sensitivity, which produces a cardiosympathetic bias and an increase in HR. ${ }^{2,24,35,90}$ The reduction in sympathetic tone, and associated decrease in circulating catecholamines observed in FMS and TMD cases, ${ }^{15}, 28,31,48,52,92$ may result in an upregulation and sensitization of $\beta$-adrenergic receptors such that when catecholamines are released into the peripheral circulation augmented HR responses are evoked under varying environmental conditions. Increases in circulating levels of catecholamines, such as epinephrine, also enhance pain sensitivity and inflammatory responses by stimulating peripheral nociceptors and suppressing the HPA axis via the stimulation of $\beta$-adrenergic receptors. ${ }^{38-41}$

\section{Implications for Treatment}

The current findings suggest that pharmacological treatments that block the effects of catecholamines should produce an analgesic effect in patients with TMD and related conditions. Consistent with this view, the non-selective $\beta$-adrenoreceptor antagonist propranolol and $\beta_{2}$-and $\beta_{3}$-adrenoreceptor selective antagonists reverse the mechanical and thermal hyperalgesia and allodynia induced by catecholamines in rodent pain models. ${ }^{38-40,66}$ The blockade of $\beta$-adrenoreceptors with the non-selective $\beta$-adrenoreceptor antagonist propranolol has also been shown to diminish clinical pain report in subpopulations of patients with TMD that carry genetic variants of COMT coding for low levels of enzyme. ${ }^{18,52,65,87}$ It is also noteworthy that $\beta$-adrenoreceptor blockade with propranolol reverses the suppression of the HPA axis resulting in an increase the secretion of cortisol ${ }^{41}$ and enhances baroreflexes in man. ${ }^{17,20,24}$ These findings suggest that the augmented sympathetic drive, which is indexed by increased HR and impaired baroreceptor sensitivity, contributes to the clinical signs and symptoms seen in TMD and related conditions and that $\beta$-adrenoreceptor antagonists, such as propranolol, may prove effective in treating large subpopulations of TMD patients.

The current findings also suggest that non-pharmacological treatments that increase HRV such as exercise ${ }^{23}$, breathing control ${ }^{11,50}$, intraoral orthotics ${ }^{14}$ and interventions that improve self regulatory strength ${ }^{83}$ may prove to be effective in treating TMD and related conditions. As discussed by Schmidt and coworkers, ${ }^{81}$ and demonstrated by Lehrer and coworkers $^{49,50,89}$, biofeedback training using HRV increases vagal tone, parasympathetic activation, and baroreflex gain. The degree to which manipulations that increase HRV and baroreflex sensitivity are able to diminish pain and increase function in patients with TMD and related conditions by restoring brainstem mediated inhibitory systems remains an open and interesting question.

\section{Age, Gender, and Race/Ethnicity -- Autonomic Profiles}

Age-The observation that resting and stress-evoked changes result in arterial blood pressure increase and HRV decrease as a function of age is consistent with previous literature. $3,5,32,33,47,75,93$ Resting HR and HR values during physical and psychological stressors were not associated with age and suggest that the observed elevations in arterial blood pressure result from an age-dependency on $\alpha_{1}$-adrenoceptor mediated increases in peripheral vascular resistance and/or arterial structural changes that produce arterial stiffening. The observed age-dependent reduction in HRV is consistent with decreased autonomic responses to physical and emotional stress and an age-dependent reduction in baroreceptor sensitivity. While speculative, this autonomic profile may contribute to age- 
dependent increases in clinical pain conditions, clinical pain report and is consistent with the observation that the prevalence of chronic TMD increases as a function of age (see Slade et al. in this volume), at least in the restricted age range (18-44) studied in our OPPERA study.

Gender-The finding that females have lower arterial blood values, higher heart rate values, and deceased HRV values at rest and during physical and psychological stressors is consistent with multiple reports. $5,27,43,63,85$ The elevation in HR across experimental conditions in females is consistent with the view that females show enhanced $\beta$-adrenergic drive as a consequence of reduced baroreceptor sensitivity resulting in a cardiosympathetic bias. The reduction in HRV in females is also consistent with attenuated autonomic responses to physical and emotional stress. This profile is consistent with the observation that females are generally more pain sensitive (see Greenspan et al. in this volume) and are more likely to suffer from chronic TMD (see Slade et al. this volume) and related conditions.

Race/Ethnicity-The observation that whites have lower arterial blood pressure and HR reactivity to stressor as well as increased LF and VLF values compared to non-whites is consistent with previous studies that have shown that African Americans have higher resting arterial blood pressures, increased BP and HR responses to stress, and diminished baroreceptor sensitivity compared to whites. 4, 36, 44, 51, 64 In African Americans, this autonomic profile is associated with both an increase in cardiosympathetic tone ( $\beta$ adrenergic mediated) and increased peripheral vascular resistance ( $\alpha_{1}$-adrenergic mediated). Based on the white vs non-white autonomic profiles one would predict that chronic TMD and related conditions should be more prevalent in African American compared to whites. Current experimental evidence provided by Plesh et $\mathrm{al}^{73}$ and Slade et al. (in this volume) does not support this prediction, which suggest that unknown race/ethnicity specific genetic and/or environmental factors produce protective effects in African Americans compared to whites. One possible protective factor is the increase prevalence of hypertension in the African American population, which may confer protective effects on the development of chronic pain conditions. ${ }^{9}, 25,29,30,55,56,76$

Latent Constructs Revealed by PCA-The various blood pressure measurements all loaded on one component, as did all of the HR measurements. However, the HRV measurements loaded on three different components, with each component corresponding to a different epoch. This suggests that all the blood pressure measurements are highly correlated with one another and that measuring blood pressure during different epochs provides minimal additional information beyond the information obtained from measuring blood pressure during a single epoch. Likewise, DBP and MAP provide minimal additional information if SBP is known (and likewise for DBP and MAP). Similarly, if heart rate is measured in one epoch, there is minimal information to be gained by measuring heart rate during other epochs. One the other hand, the HRV measurements at baseline loaded on a different component than the HRV measurements during the orthostatic challenge, and both of these measurement sets loaded on a different component than the HRV measurements during the Stroop procedures. This indicates that a person's HRV at baseline is an imperfect predictor of their HRV measurements during the orthostatic challenge or the Stroop procedure and that we may gain additional information about a subject's autonomic profile by measuring their HRV in the three separate epochs.

Our PCA results should be viewed as exploratory, and further confirmation of these results is necessary. A logical next step would be to attempt to reproduce these results in a future study. If our model can be reproduced, these latent constructs identified by the model will be a useful tool for future research. If several different measurements (i.e. systolic and diastolic blood pressure in different epochs) are all strongly correlated measures of the same 
underlying construct, then it is likely that we can reduce the number of measurements collected in future studies with minimal loss of information. These latent constructs may also be evaluated as possible risk factors for new onset TMD.

\section{Limitations}

There are a few limitations that should be kept in mind. Given the size of the cohort, the primary aims of OPPERA, and the need to develop a high throughput means of collecting and analyzing HRV data, post-collection raw signal artifact assessment and correction was not performed. Instead, the quality of the ECG signal was evaluated by staff during the recording sessions and real-time artifact detection and rejection were conducted using Biocom Heart Rhythm Scanner software. In addition, several steps were taken to review and filter out-of -range values as described in the Methods section. A second limitation is that we did not directly assess baroreflex sensitivity, but as noted above the LF band has been shown to be a valid surrogate measure of baroreflex sensitivity. However, additional studies are required that provide a more definitive assessment of the role that baroreflex function plays in TMD and related conditions. Finally, it should be noted that many of the SOR's associated with case-status were relatively small, ranging from 1.2-2.2, which may challenge the "clinical" meaningfulness of the findings. However, a variable with an odds ratio of 1.2 could still be very important if it is approximately orthogonal to the other measured variables. Additional multivariate modeling is required, and will be conducted in the future, to more specifically address the relative importance of these variables, but currently this is beyond the goals of the present analysis.

\section{Conclusions and Future Directions}

This is the first large-scale case-control study that has examined autonomic profiles in TMD at rest and in response to physical and psychological stressors. TMD is associated with a bias towards enhanced cardiosympathetic tone and a possible decrease in baroreflex sensitivity, which is indexed by relatively low LF values at rest and during the application of physical and psychological stressors. The clinical importance and causal relationship of these findings as they relate to TMD onset and chronicity remain to be determined. Future analyzes will examine the relationship between these findings and other phenotypic risk factors and genetic polymorphisms. Finally, the OPPERA team intends to use the results of this study to develop and validate cluster and multivariate models that represent explanatory causal models that integrate putative risk determinates for TMD onset and chronicity.

\section{Supplementary Material}

Refer to Web version on PubMed Central for supplementary material.

\section{Acknowledgments}

The authors would like to thank the OPPERA research staff for their invaluable contributions to this work. In addition, we express our gratitude to the research participants who have devoted time and effort in support of this research.

\section{References}

1. Heart rate variability. Standards of measurement, physiological interpretation, and clinical use. Task Force of the European Society of Cardiology and the North American Society of Pacing and Electrophysiology. Eur Heart J. 1996; 17(3):354-381. [PubMed: 8737210]

2. Abboud, FM.; Thames, MD. Interaction of cardiovascular reflexes in circulatory control. In: Shepherd, JT.; Abboud, FM., editors. Handbook of Physiology - The Cardiovascular System. Bethesda, MD: American Physiological Society; 1984. p. 675-753. 
3. Amery A, Wasir H, Bulpitt C, Conway J, Fagard R, Lijnen P, Reybrouck T. Aging and the cardiovascular system. Acta Cardiol. 1978; 33(6):443-467. [PubMed: 375649]

4. Anderson NB, Myers HF, Pickering T, Jackson JS. Hypertension in blacks: psychosocial and biological perspectives. J Hypertens. 1989; 7(3):161-172. [PubMed: 2651519]

5. Barantke M, Krauss T, Ortak J, Lieb W, Reppel M, Burgdorf C, Pramstaller PP, Schunkert H, Bonnemeier H. Effects of gender and aging on differential autonomic responses to orthostatic maneuvers. J Cardiovasc Electrophysiol. 2008; 19(12):1296-1303. [PubMed: 18662181]

6. Berntson GG, Bigger JT Jr, Eckberg DL, Grossman P, Kaufmann PG, Malik M, Nagaraja HN, Porges SW, Saul JP, Stone PH, van der Molen MW. Heart rate variability: origins, methods, and interpretive caveats. Psychophysiology. 1997; 34(6):623-648. [PubMed: 9401419]

7. Bou-Holaigah I, Calkins H, Flynn JA, Tunin C, Chang HC, Kan JS, Rowe PC. Provocation of hypotension and pain during upright tilt table testing in adults with fibromyalgia. Clin Exp Rheumatol. 1997; 15(3):239-246. [PubMed: 9177917]

8. Bragdon EE, Light KC, Costello NL, Sigurdsson A, Bunting S, Bhalang K, Maixner W. Group differences in pain modulation: pain-free women compared to pain-free men and to women with TMD. Pain. 2002; 96(3):227-237. [PubMed: 11972994]

9. Bruehl S, Chung OY. Interactions between the cardiovascular and pain regulatory systems: an updated review of mechanisms and possible alterations in chronic pain. Neurosci Biobehav Rev. 2004; 28(4):395-414. [PubMed: 15341037]

10. Carlson CR, Okeson JP, Falace DA, Nitz AJ, Curran SL, Anderson D. Comparison of psychologic and physiologic functioning between patients with masticatory muscle pain and matched controls. Jour of Orofacial Pain. 1993; 7:15-22. [PubMed: 8467294]

11. Carlson CR, Bertrand PM, Ehrlich AD, Maxwell AW, Burton RG. Physical self-regulation training for the management of temporomandibular disorders. J Orofac Pain. 2001; 15(1):47-55. [PubMed: 11889647]

12. Ciriello J, Caverson MM, Polosa C. Function of the ventrolateral medulla in the control of the circulation. Brain Res Rev. 1986; 11:359-391.

13. Cohen H, Neumann L, Shore M, Amir M, Cassuto Y, Buskila D. Autonomic dysfunction in patients with fibromyalgia: Application of power spectral analysis of heart rate variability. Semin Arthritis Rheum. 2000; 29(4):217-227. [PubMed: 10707990]

14. Coruzzi P, Gualerzi M, Bernkopf E, Brambilla L, Brambilla V, Broia V, Lombardi C, Parati G. Autonomic cardiac modulation in obstructive sleep apnea: effect of an oral jaw-positioning appliance. Chest. 2006; 130(5):1362-1368. [PubMed: 17099011]

15. Costello NL, Bragdon EE, Light KC, Sigurdsson A, Bunting S, Grewen K, Maixner W. Temporomandibular disorder and optimism: relationships to ischemic pain sensitivity and interleukin-6. Pain. 2002; 100(1-2):99-110. [PubMed: 12435463]

16. de Abreu TC, Nilner M, Thulin T, Vallon D. Office and ambulatory blood pressure in patients with craniomandibular disorders. Acta Odontol Scand. 1993; 51(3):161-170. [PubMed: 8342407]

17. Deering AH, Harron DW, Riddell JG, Shanks RG. Effect of acute administration of propranolol and atenolol on baroreflex function in normal man. Eur J Clin Pharmacol. 1988; 35(6):607-612. [PubMed: 3148471]

18. Diatchenko L, Slade GD, Nackley AG, Bhalang K, Sigurdsson A, Belfer I, Goldman D, Xu K, Shabalina SA, Shagin D, Max MB, Makarov SS, Maixner W. Genetic basis for individual variations in pain perception and the development of a chronic pain condition. Hum Mol Genet. 2005; 14(1):135-143. [PubMed: 15537663]

19. Diatchenko L, Nackley AG, Slade GD, Fillingim RB, Maixner W. Idiopathic pain disorders-pathways of vulnerability. Pain. 2006; 123(3):226-230. [PubMed: 16777329]

20. Eckberg DL, Abboud FM, Mark AL. Modulation of carotid baroreflex responsiveness in man: effects of posture and propranolol. J Appl Physiol. 1976; 41(3):383-387. [PubMed: 965307]

21. Efron, B.; Tibshirani, R. An Introduction to Bootstrap. Boca Raton, FL: Chapman \& Hall/CRC; 1994.

22. Elam M, Johansson G, Wallin BG. Do patients with primary fibromyalgia have an altered muscle sympathetic nerve activity? Pain. 1992; 48(3):371-375. [PubMed: 1594259] 
23. Figueroa A, Kingsley JD, McMillan V, Panton LB. Resistance exercise training improves heart rate variability in women with fibromyalgia. Clin Physiol Funct Imaging. 2008; 28(1):49-54. [PubMed: 18005081]

24. Floras JS, Jones JV, Hassan MO, Sleight P. Effects of acute and chronic beta-adrenoceptor blockade on baroreflex sensitivity in humans. J Auton Nerv Syst. 1988; 25(2-3):87-94. [PubMed: 2906953]

25. France CR. Decreased pain perception and risk for hypertension: considering a common physiological mechanism. Psychophysiology. 1999; 36(6):683-692. [PubMed: 10554582]

26. Furlan R, Colombo S, Perego F, Atzeni F, Diana A, Barbic F, Porta A, Pace F, Malliani A, SarziPuttini P. Abnormalities of cardiovascular neural control and reduced orthostatic tolerance in patients with primary fibromyalgia. J Rheumatol. 2005; 32(9):1787-1793. [PubMed: 16142879]

27. Girdler SS, Turner JR, Sherwood A, Light KC. Gender differences in blood pressure control during a variety of behavioral stressors. Psychosomatic Med. 1990; 52:571-591.

28. Giske L, Vøllestad NK, Mengshoel AM, Jensen J, Knardahl S, Røe C. Attenuated adrenergic responses to exercise in women with fibromyalgia - A controlled study. European Journal of Pain. 2008; 12(3):351-360. [PubMed: 17827042]

29. Hagen K, Stovner LJ, Vatten L, Holmen J, Zwart JA, Bovim G. Blood pressure and risk of headache: a prospective study of 22685 adults in Norway. J Neurol Neurosurg Psychiatry. 2002; 72(4):463-466. [PubMed: 11909904]

30. Hagen K, Zwart JA, Holmen J, Svebak S, Bovim G, Stovner LJ. Nord-Trondelag Health Study. Does hypertension protect against chronic musculoskeletal complaints? The Nord-Trondelag Health Study. Arch Intern Med. 2005; 165(8):916-922. [PubMed: 15851644]

31. Hamaty D, Valentine JL, Howard R, Howard CW, Wakefield V, Patten MS. The plasma endorphin, prostaglandin and catecholamine profile of patients with fibrositis treated with cyclobenzaprine and placebo: a 5-month study. J Rheumatol Suppl. 1989; 19:164-168. [PubMed: 2532682]

32. Hotta H, Uchida S. Aging of the autonomic nervous system and possible improvements in autonomic activity using somatic afferent stimulation. Geriatr Gerontol Int. 2010; 10(Suppl 1):S127-36. [PubMed: 20590828]

33. Huang CC, Sandroni P, Sletten DM, Weigand SD, Low PA. Effect of age on adrenergic and vagal baroreflex sensitivity in normal subjects. Muscle Nerve. 2007; 36(5):637-642. [PubMed: 17654557]

34. Hugdahl, K. Psychophysiology: The Mind-Body Perspective. London: Harvard University Press; 2001.

35. Julius S, Esler M. Autonomic nervous cardiovascular regulation in borderline hypertension. Am J Cardiol. 1975; 36(5):685-696. [PubMed: 171939]

36. Kailasam MT, O'Connor DT, Parmer RJ. Hereditary intermediate phenotypes in African American hypertension. Ethn Health. 1996; 1(2):117-128. [PubMed: 9395555]

37. Kelemen J, Lang E, Balint G, Trocsanyi M, Muller W. Orthostatic sympathetic derangement of baroreflex in patients with fibromyalgia. J Rheumatol. 1998; 25(4):823-825. [PubMed: 9558200]

38. Khasar SG, Miao FJ, Janig W, Levine JD. Vagotomy-induced enhancement of mechanical hyperalgesia in the rat is sympathoadrenal-mediated. J Neurosci. 1998; 18(8):3043-3049. [PubMed: 9526021]

39. Khasar SG, McCarter G, Levine JD. Epinephrine produces a beta-adrenergic receptor-mediated mechanical hyperalgesia and in vitro sensitization of rat nociceptors. J Neurophysiol. 1999; 81(3): 1104-1112. [PubMed: 10085337]

40. Khasar SG, Green PG, Miao FJ, Levine JD. Vagal modulation of nociception is mediated by adrenomedullary epinephrine in the rat. Eur J Neurosci. 2003; 17(4):909-915. [PubMed: 12603283]

41. Kizildere S, Gluck T, Zietz B, Scholmerich J, Straub RH. During a corticotropin-releasing hormone test in healthy subjects, administration of a beta-adrenergic antagonist induced secretion of cortisol and dehydroepiandrosterone sulfate and inhibited secretion of ACTH. Eur J Endocrinol. 2003; 148(1):45-53. [PubMed: 12534357] 
42. Laederach-Hofmann K, Ruddel H, Mussgay L. Pathological baroreceptor sensitivity in patients suffering from somatization disorders: do they correlate with symptoms? Biol Psychol. 2008; 79(2):243-249. [PubMed: 18611426]

43. Laitinen T, Hartikainen J, Vanninen E, Niskanen L, Geelen G, Lansimies E. Age and gender dependency of baroreflex sensitivity in healthy subjects. J Appl Physiol. 1998; 84(2):576-583. [PubMed: 9475868]

44. Lampert R, Ickovics J, Horwitz R, Lee F. Depressed autonomic nervous system function in African Americans and individuals of lower social class: a potential mechanism of race- and class-related disparities in health outcomes. Am Heart J. 2005; 150(1):153-160. [PubMed: 16084163]

45. Langewitz W, Ruddel H, Schachinger H, Lepper W, Mulder LJ, Veldman JH, van Roon A. Changes in sympathetic and parasympathetic cardiac activation during mental load: an assessment by spectral analysis of heart rate variability. Homeost Health Dis. 1991; 33(1-2):23-33. [PubMed: 1817688]

46. Last JM, Spasoff RA, Harris SS, Thuriaux MC. Epidemiological Association: A Dictionary of Epidemiology. 2001

47. Lee HY, Oh BH. Aging and arterial stiffness. Circ J. 2010; 74(11):2257-2262. [PubMed: 20962429]

48. Legangneux E, Mora JJ, Spreux-Varoquaux O, Thorin I, Herrou M, Alvado G, Gomeni C. Cerebrospinal fluid biogenic amine metabolites, plasma-rich platelet serotonin and [3H]imipramine reuptake in the primary fibromyalgia syndrome. Rheumatology. 2001; 40(3):290296. [PubMed: 11285376]

49. Lehrer PM, Vaschillo E, Vaschillo B, Lu SE, Eckberg DL, Edelberg R, Shih WJ, Lin Y, Kuusela TA, Tahvanainen KU, Hamer RM. Heart rate variability biofeedback increases baroreflex gain and peak expiratory flow. Psychosom Med. 2003; 65(5):796-805. [PubMed: 14508023]

50. Lehrer, PM. Biofeedback training to increase heart rate variability. In: Lehrer, PM.; woolfolk, RL.; Sime, WE., editors. Principles and Practice of Stress Management. New York: Guilford Press; 2007. p. 227-248.

51. Light KC, Obrist PA, Sherwood A, James SA, Strogatz DS. Effects of race and marginally elevated blood pressure on responses to stress. Hypertension. 1987; 10(6):555-563. [PubMed: 3692569]

52. Light KC, Bragdon EE, Grewen KM, Brownley KA, Girdler SS, Maixner W. Adrenergic dysregulation and pain with and without acute beta-blockade in women with fibromyalgia and temporomandibular disorder. J Pain. 2009; 10(5):542-552. [PubMed: 19411061]

53. Maekawa K, Clark GT, Kuboki T. Intramuscular hypoperfusion, adrenergic receptors, and chronic muscle pain. J Pain. 2002; 3(4):251-260. [PubMed: 14622746]

54. Maekawa K, Kuboki T, Inoue E, Inoue-Minakuchi M, Suzuki K, Yatani H, Clark GT. Function of beta 2-adrenergic receptors in chronic localized myalgia. J Orofac Pain. 2003; 17(2):140-144. [PubMed: 12836502]

55. Maixner W, Touw KB, Brody MJ, Gebhart GF, Long JP. Factors influencing the altered pain perception in the spontaneously hypertensive rat. Brain Res. 1982; 237(1):137-145. [PubMed: 6122488]

56. Maixner W. Interactions between cardiovascular and pain modulatory systems: physiological and pathophysiological implications. J Cardiovas Electrophysiol (Supplement). 1991; 2 :S2-S12.

57. Maixner, W.; Sigurdsson, A.; Fillingim, R.; Lundeen, T.; Booker, D. Regulation of acute and chronic orofacial pain. In: Fricton, JR.; Dubner, RB., editors. Orofacial Pain and Temporomandibular Disorders. New York: Raven Press, Ltd; 1995. p. 85-102.

58. Maixner W, Fillingim R, Kincaid S, Sigurdsson A, Harris MB. Relationship between pain sensitivity and resting arterial blood pressure in patients with painful temporomandibular disorders. Psychosom Med. 1997; 59(5):503-511. [PubMed: 9316183]

59. Maixner, W. Biopsychological and Genetic Risk Factors for Temporomandibular Joint Disorders and Related Conditions. In: Graven-Nielsen, T.; Arendt-Nielsen, L.; Mense, S., editors. Fundamentals of Musculoskeletal Pain. Seattle: IASP Press; 2008. p. 263-279. 
60. Martinez-Lavin M, Hermosillo AG, Mendoza C, Ortiz R, Cajigas JC, Pineda C, Nava A, Vallejo M. Orthostatic sympathetic derangement in subjects with fibromyalgia. J Rheumatol. 1997; 24(4): 714-718. [PubMed: 9101507]

61. Martinez-Lavin M, Hermosillo AG. Dysautonomia in Gulf War syndrome and in fibromyalgia. Am J Med. 2005; 118(4):446. [PubMed: 15808150]

62. Martinez-Lavin M. Biology and therapy of fibromyalgia. Stress, the stress response system, and fibromyalgia. Arthritis Res Ther. 2007; 9(4):216. [PubMed: 17626613]

63. Matthews KA, Stoney CM. Influences of sex and age on cardiovascular responses during stress. Psychosom Med. 1988; 50:46-56. [PubMed: 3344302]

64. Murphy JK, Alpert BS, Moes DM, Somes GW. Race and cardiovascular reactivity. A neglected relationship. Hypertension. 1986; 8(11):1075-1083. [PubMed: 3770868]

65. Nackley AG, Shabalina SA, Tchivileva IE, Satterfield K, Korchynskyi O, Makarov SS, Maixner W, Diatchenko L. Human catechol-O-methyltransferase haplotypes modulate protein expression by altering mRNA secondary structure. Science. 2006; 314(5807):1930-1933. [PubMed: 17185601]

66. Nackley AG, Tan KS, Fecho K, Flood P, Diatchenko L, Maixner W. Catechol-O-methyltransferase inhibition increases pain sensitivity through activation of both beta2- and beta3-adrenergic receptors. Pain. 2007; 128(3):199-208. [PubMed: 17084978]

67. Naschitz JE, Rozenbaum M, Rosner I, Sabo E, Priselac RM, Shaviv N, Ahdoot A, Ahdoot M, Gaitini L, Eldar S, Yeshurun D. Cardiovascular response to upright tilt in fibromyalgia differs from that in chronic fatigue syndrome. J Rheumatol. 2001; 28(6):1356-1360. [PubMed: 11409131]

68. Perry F, Heller PH, Kamiya J, Levine JD. Altered autonomic function in patients with arthritis or with chronic myofacial pain. Pain. 1989; 39:77-84. [PubMed: 2812855]

69. Pett, MA.; Lackey, NR.; Sullivan, JJ. Making sense of factor analysis: the use of factor analysis for instrument development in health care research. Thousand Oaks, CA: Sage Publications; 2003.

70. Petzke F, Clauw DJ. Sympathetic nervous system function in fibromyalgia. Curr Rheumatol Rep. 2000; 2(2):116-123. [PubMed: 11123048]

71. Pincus T, Fraser L, Pearce S. Do chronic pain patients 'Stroop' on pain stimuli? Br J Clin Psychol. 1998; 37(Pt 1):49-58. [PubMed: 9547959]

72. Pinna GD. Assessing baroreflex sensitivity by the transfer function method: what are we really measuring? J Appl Physiol. 2007; 102(4):1310-1311. [PubMed: 17218433]

73. Plesh O, Crawford PB, Gansky SA. Chronic pain in a biracial population of young women 1. Pain. 2002; 99(3):515-523. [PubMed: 12406528]

74. Raj SR, Brouillard D, Simpson CS, Hopman WM, Abdollah H. Dysautonomia among patients with fibromyalgia: a noninvasive assessment. J Rheumatol. 2000; 27(11):2660-2665. [PubMed: 11093450]

75. Randall OS, Esler MD, Bulloch EG, Maisel AS, Ellis CN, Zweifler AJ, Julius S. Relationship of age and blood pressure to baroreflex sensitivity and arterial compliance in man. Clin Sci Mol Med Suppl. 1976; 3:357s-360s. [PubMed: 1071645]

76. Randich A, Maixner W. Interactions between cardiovascular and pain regulatory systems. Neurosci Biobehav Rev. 1984; 8:343-367. [PubMed: 6095151]

77. Randich A, Maixner W. The role of sinoaortic and cardiopulmonary baroreceptor reflex arcs in nociception and stress-induced analgesia. Ann N Y Acad Sci. 1986; 467:385-401. [PubMed: 3524386]

78. Reyes Del Paso GA, Garrido S, Pulgar A, Martin-Vazquez M, Duschek S. Aberrances in autonomic cardiovascular regulation in fibromyalgia syndrome and their relevance for clinical pain reports. Psychosom Med. 2010; 72(5):462-470. [PubMed: 20467004]

79. Reyes Del Paso GA, Garrido S, Pulgar A, Duschek S. Autonomic cardiovascular control and responses to experimental pain stimulation in fibromyalgia syndrome. J Psychosom Res. 2011; 70(2):125-134. [PubMed: 21262414]

80. Roderick, JA.; Little, RJA.; Rubin, RB. Statistical Analysis with Missing Data. Hoboken, NJ: John Wiley \& Sons; 2002. p. 408 
81. Schmidt JE, Carlson CR. A controlled comparison of emotional reactivity and physiological response in masticatory muscle pain patients. J Orofac Pain. 2009; 23(3):230-242. [PubMed: 19639103]

82. Sleight P, La Rovere MT, Mortara A, Pinna G, Maestri R, Leuzzi S, Bianchini B, Tavazzi L, Bernardi L. Physiology and pathophysiology of heart rate and blood pressure variability in humans: is power spectral analysis largely an index of baroreflex gain? Clin Sci (Lond). 1995; 88(1):103-109. [PubMed: 7677832]

83. Solberg Nes L, Carlson CR, Crofford LJ, Leeuw RD, Segerstrom SC. Self-regulatory deficits in fibromyalgia and temporomandibular disorders. Pain. 2010

84. Staud R. Heart rate variability as a biomarker of fibromyalgia syndrome. Fut Rheumatol. 2008; 3(5):475-483. [PubMed: 19890437]

85. Stoney CM, Davis MC, Matthews KA. Sex differences in physiological responses to stress and coronary heart disease: A casual link? Psychophysiology. 1987; 24:127-131. [PubMed: 3602263]

86. Stroop JR. Studies of interference in serial verbal reactions. 1935; $18: 643-662$.

87. Tchivileva IE, Lim PF, Smith SB, Slade GD, Diatchenko L, McLean SA, Maixner W. Effect of catechol-O-methyltransferase polymorphism on response to propranolol therapy in chronic musculoskeletal pain: a randomized., double-blind, placebo-controlled, crossover pilot study. Pharmacogenet Genomics. 2010; 20(4):239-248. [PubMed: 20216107]

88. van de Vooren H, Gademan MG, Swenne CA, TenVoorde BJ, Schalij MJ, Van der Wall EE. Baroreflex sensitivity, blood pressure buffering, and resonance: what are the links? Computer simulation of healthy subjects and heart failure patients. J Appl Physiol. 2007; 102(4):1348-1356. [PubMed: 17185500]

89. Vaschillo E, Lehrer P, Rishe N, Konstantinov M. Heart rate variability biofeedback as a method for assessing baroreflex function: a preliminary study of resonance in the cardiovascular system. Appl Psychophysiol Biofeedback. 2002; 27(1):1-27. [PubMed: 12001882]

90. Volpe M, Trimarco B, Ricciardelli B, Vigorito C, de Luca N, Rengo F, Condorelli M. The autonomic nervous tone abnormalities in the genesis of the impaired baroreflex responsiveness in borderline hypertensive subjects. Clin Sci (Lond). 1982; 62(6):581-588. [PubMed: 7083750]

91. Weissman-Fogel I, Moayedi M, Tenenbaum HC, Goldberg MB, Freeman BV, Davis KD. Abnormal cortical activity in patients with temporomandibular disorder evoked by cognitive and emotional tasks. Pain. 2011; 152(2):384-396. [PubMed: 21167644]

92. Yunus MB, Dailey JW, Aldag JC, Masi AT, Jobe PC. Plasma and urinary catecholamines in primary fibromyalgia: a controlled study. J Rheumatol. 1992; 19(1):95-97. [PubMed: 1556708]

93. Zulfiqar U, Jurivich DA, Gao W, Singer DH. Relation of high heart rate variability to healthy longevity. Am J Cardiol. 2010; 105(8):1181-1185. [PubMed: 20381674] 


\section{Perspective}

This article reports autonomic findings from the OPPERA Study, a large prospective cohort study designed to discover causal determinants of TMD pain. Findings indicate statistically significant differences between TMD cases and controls across multiple autonomic constructs at rest and during both physical and psychologically challenging conditions. Future analyses will determine whether these autonomic factors increase risk for new onset TMD. 


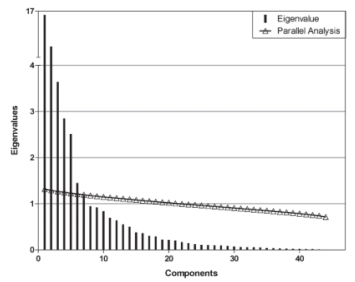

Figure 1.

Scree plot and parallel analysis from PCA. The vertical lines depict the eigenvalues for each component, showing a significant drop off after component 5. Also, the open triangles and red line show the eigenvalues that would be expected for each component from a PCA computed on a random data set. As can be seen, the observed eigenvalues for the first 5 components exceed the chance line, further supporting the selection of a 5 component model. 


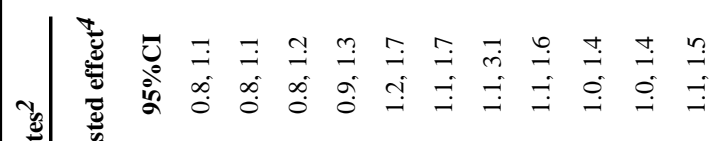

औิ

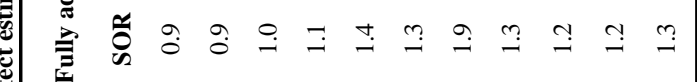

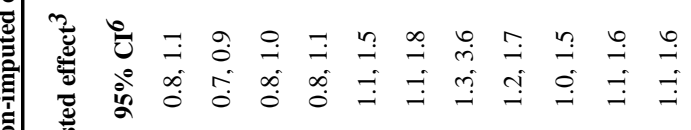
¿े

离

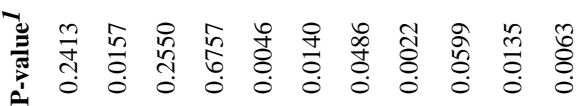

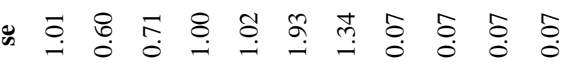
峞

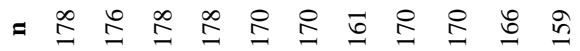
๓

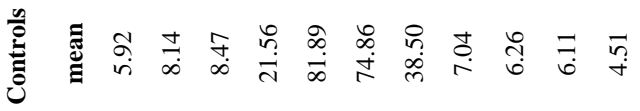

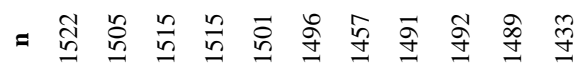

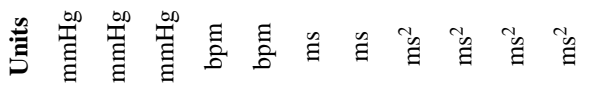

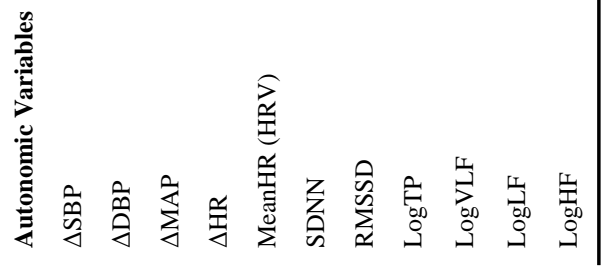




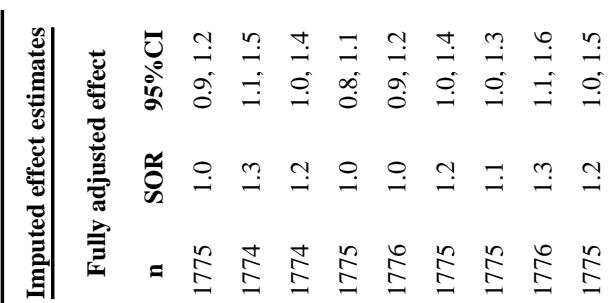

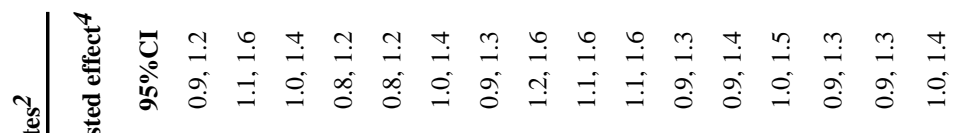

䜦

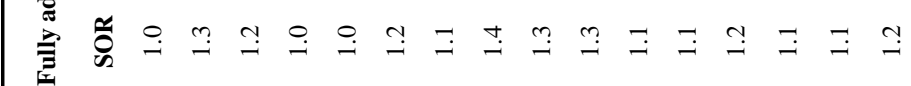

这

言

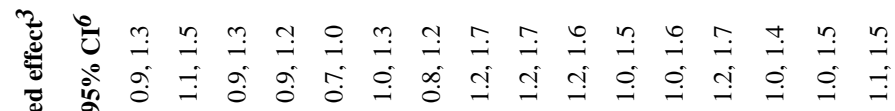
竧

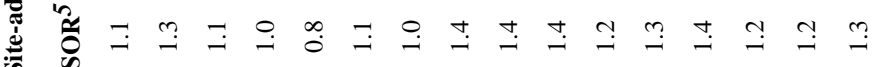

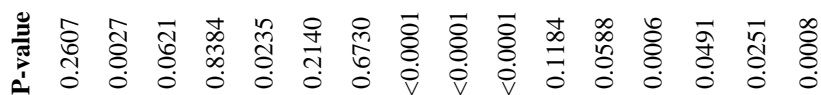

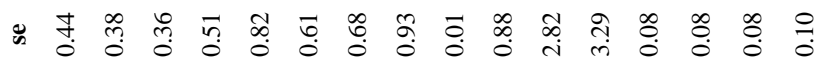

遶

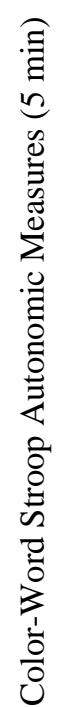

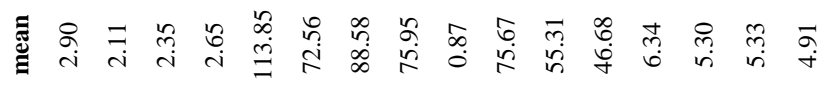

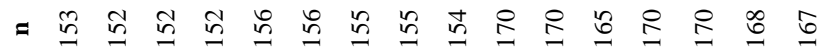

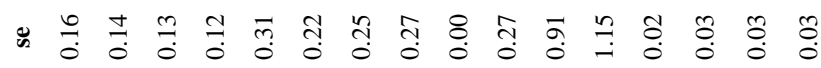
苛 $=$ f

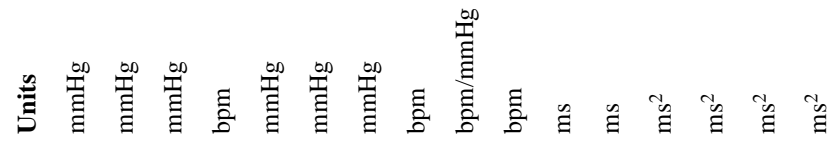

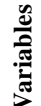

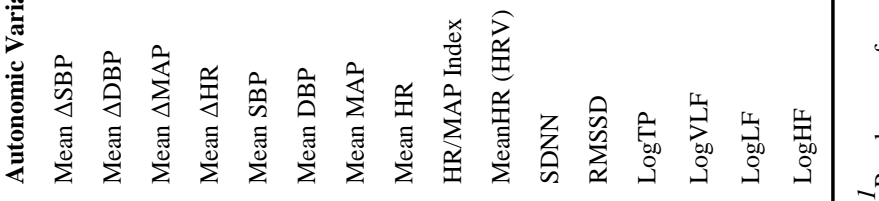




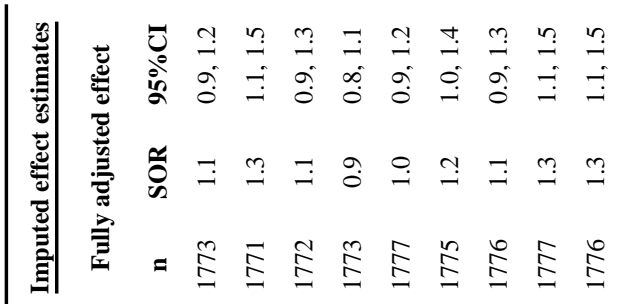

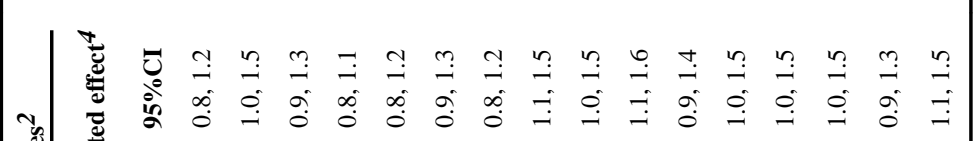

范

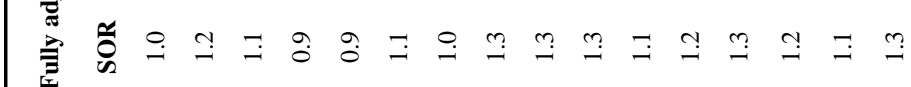

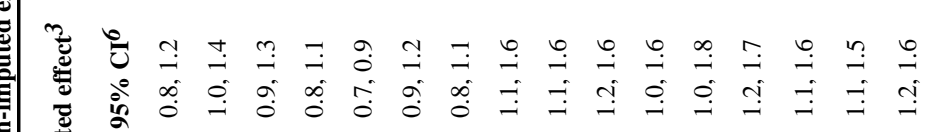

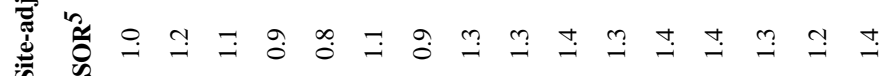

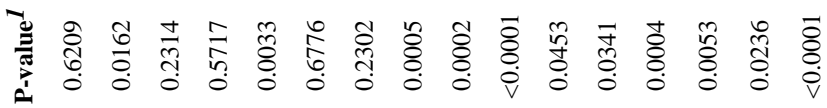

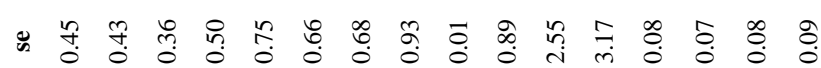

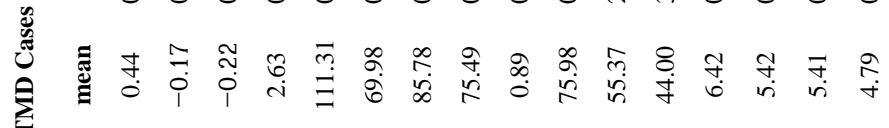

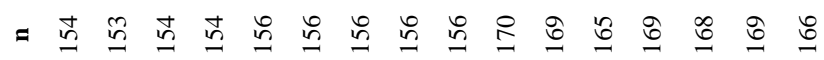

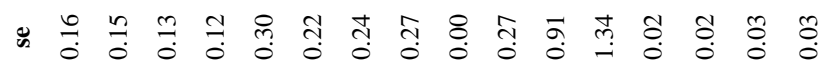

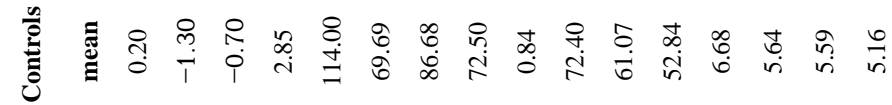

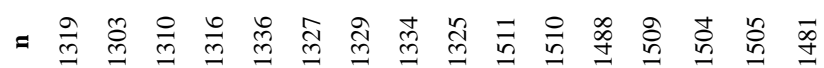

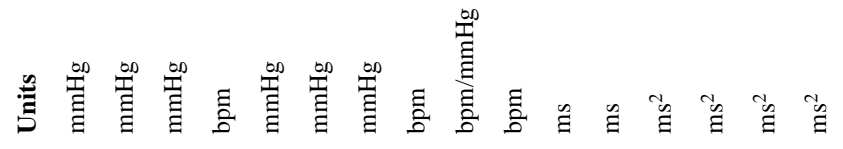

产

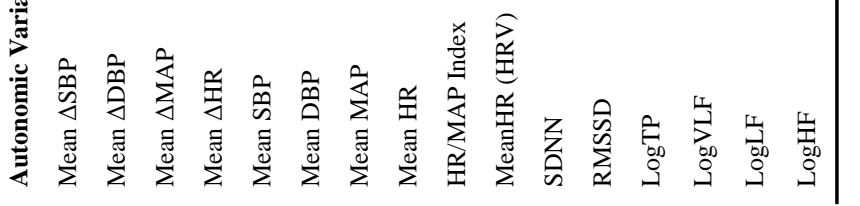

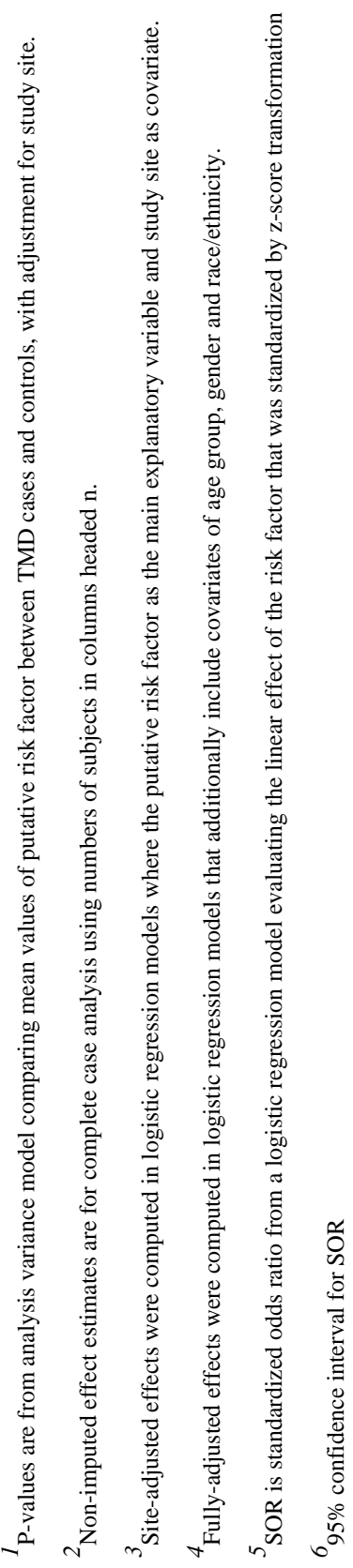



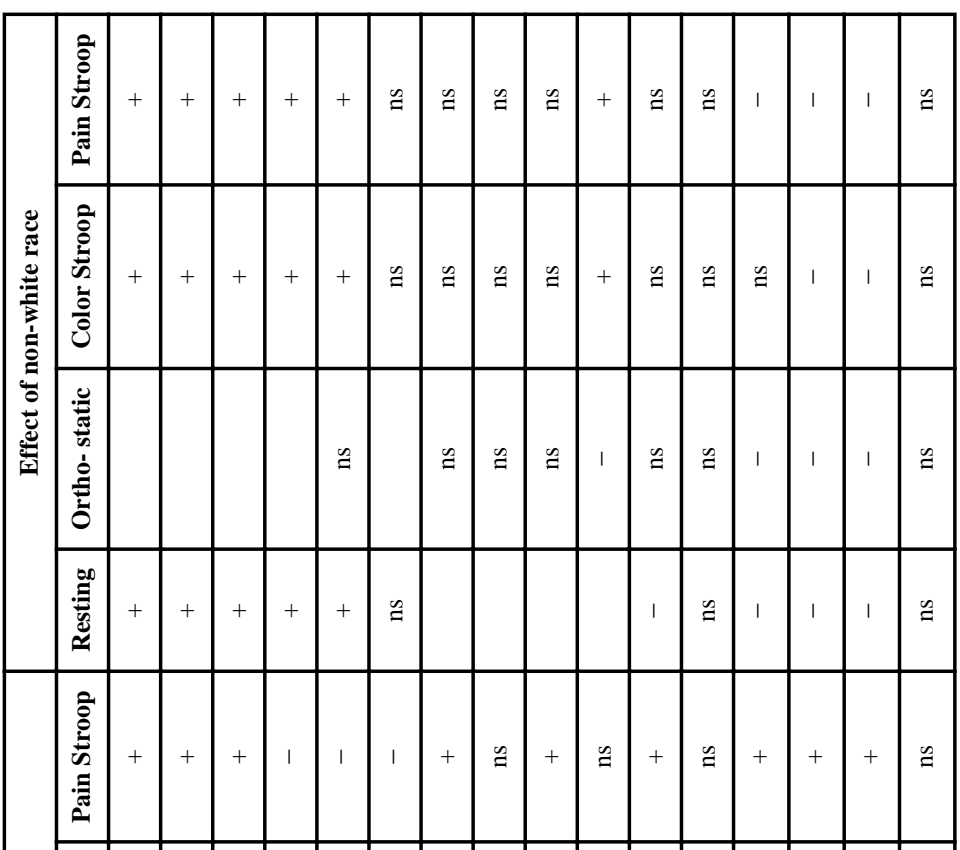

氖

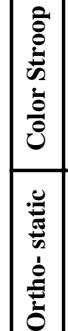

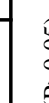

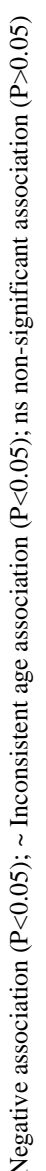




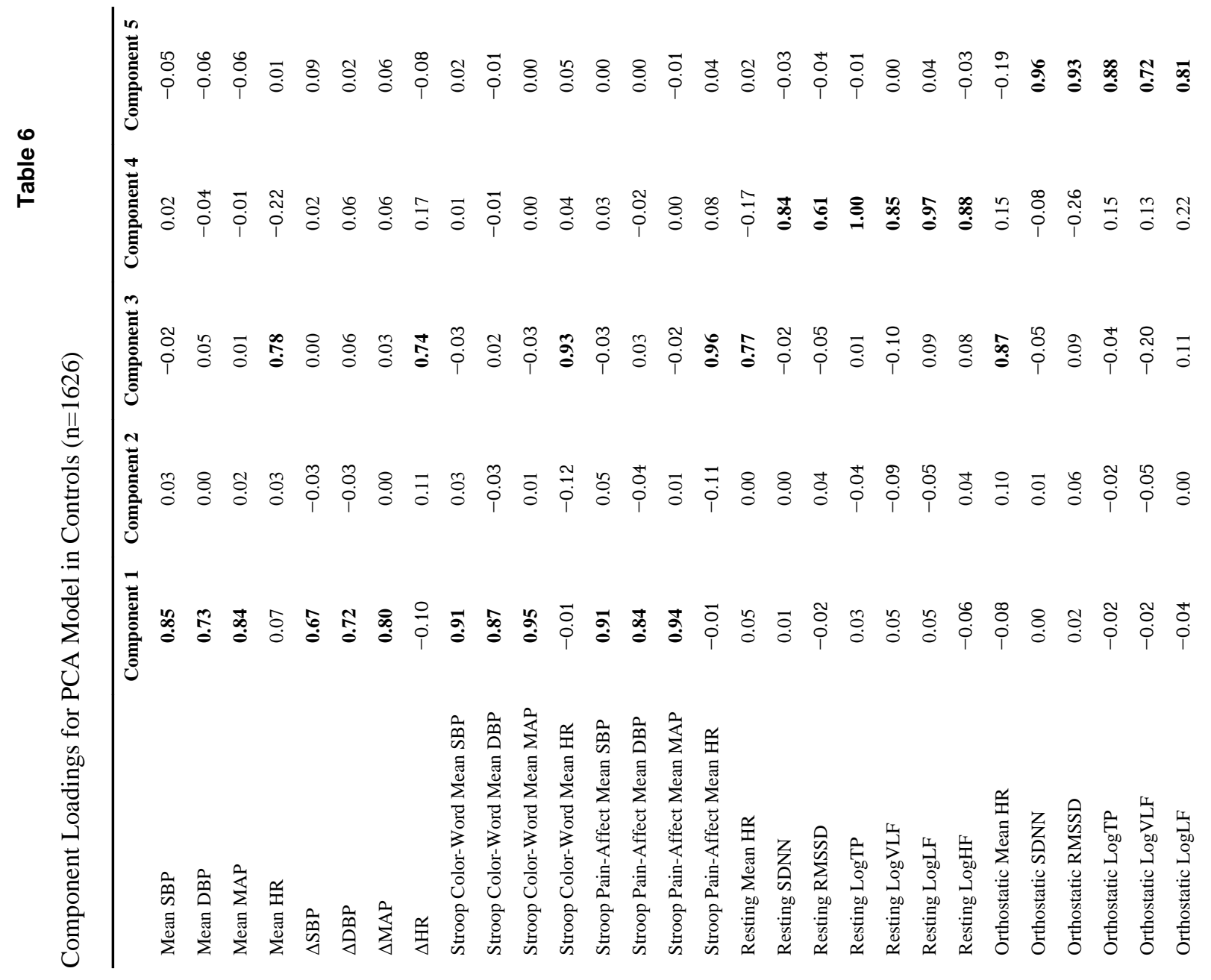




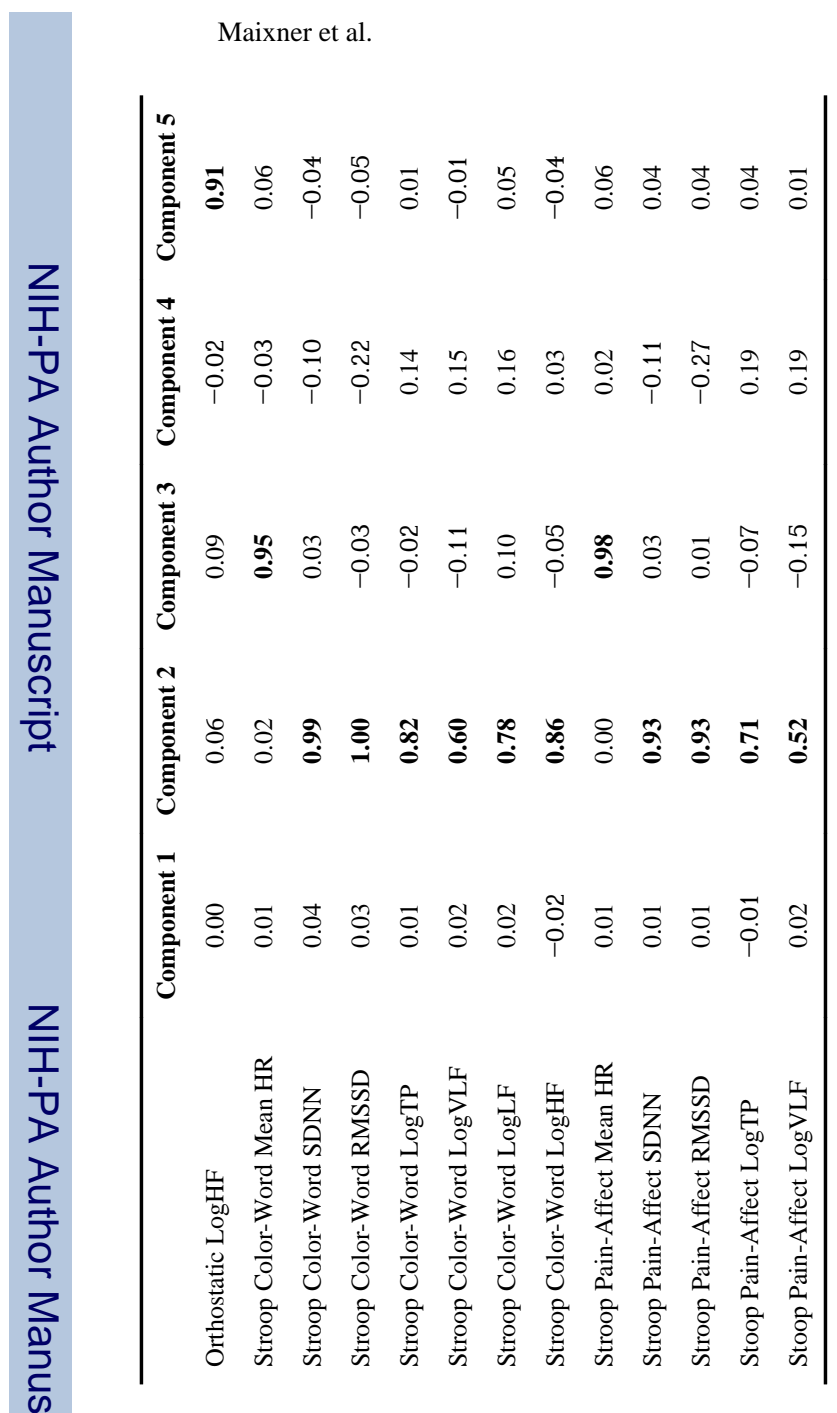

Page 30 